\title{
Treatment with paracetamol, ketorolac or etoricoxib did not hinder alveolar bone healing: a histometric study in rats
}

\author{
Ricardo Nogueira FRACON ${ }^{1}$, Juliana Mazzonetto TEÓFILO², Izabela Cristina MORIS ${ }^{3}$, Teresa LAMANO ${ }^{4}$ \\ 1- MSc, Master's degree in Oral Biology (Oral Rehabilitation), Ribeirão Preto Dental School, University of São Paulo, Ribeirão Preto, SP, Brazil. \\ 2- PhD Assistant Professor, Department of Morphology, Stomatology and Physiology, Ribeirão Preto Dental School, University of São Paulo, Ribeirão Preto, \\ SP, Brazil. \\ 3- Undergraduate student, Ribeirão Preto Dental School, University of São Paulo, Ribeirão Preto, SP, Brazil. \\ 4- Full Professor, Department of Morphology, Stomatology and Physiology, Ribeirão Preto Dental School, University of São Paulo, Ribeirão Preto, SP, Brazil.
}

Corresponding address: Dra. Teresa Lamano - Departamento de Morfologia, Estomatologia e Fisiologia - Faculdade de Odontologia de Ribeirão Preto - USP Av. do Café S/N, 14040-904 Ribeirão Preto, SP, Brasil - Phone: +55-16-3602-4012 - Fax: +55-16-3602-4794 - e-mail: tllc@forp.usp.br

Received: March 26, 2009 - Modification: January 27, 2010 - Accepted: February 11, 2010

\section{ABSTRACT}

Prostaglandins control osteoblastic and osteoclastic function under physiological or pathological conditions and are important modulators of the bone healing process. The non-steroidal anti-inflammatory drugs (NSAIDs) inhibit cyclooxygenase (COX) activity and consequently prostaglandins synthesis. Experimental and clinical evidence has indicated a risk for reparative bone formation related to the use of non-selective (COX-1 and COX-2) and COX-2 selective NSAIDs. Ketorolac is a non-selective NSAID which, at low doses, has a preferential COX-1 inhibitory effect and etoricoxib is a new selective COX-2 inhibitor. Although literature data have suggested that ketorolac can interfere negatively with long bone fracture healing, there seems to be no study associating etoricoxib with reparative bone formation. Paracetamol/acetaminophen, one of the first choices for pain control in clinical dentistry, has been considered a weak anti-inflammatory drug, although supposedly capable of inhibiting COX-2 activity in inflammatory sites. Objective: The purpose of the present study was to investigate whether paracetamol, ketorolac and etoricoxib can hinder alveolar bone formation, taking the filling of rat extraction socket with newly formed bone as experimental model. Material and Methods: The degree of new bone formation inside the alveolar socket was estimated two weeks after tooth extraction by a differential pointcounting method, using an optical microscopy with a digital camera for image capture and histometry software. Differences between groups were analyzed by ANOVA after confirming a normal distribution of sample data. Results and Conclusions: Histometric results confirmed that none of the tested drugs had a detrimental effect in the volume fraction of bone trabeculae formed inside the alveolar socket.

Key words: Bone regeneration. Paracetamol. Ketorolac. Cyclooxygenase 1. Cyclooxygenase 2. Cyclooxygenase 1 inhibitors. Cyclooxygenase 2 inhibitors.

\section{INTRODUCTION}

The cyclooxygenase enzymes cox-1 and cox2 catalyze the conversion of arachidonic acid to prostaglandins, which, in addition to a variety of physiological functions, are also involved in several pathological processes. The non-steroidal antiinflammatory drugs (NSAIDs) inhibit COX activity and consequently prostaglandin synthesis ${ }^{24}$. A wide array of NSAIDs is currently available, notably the conventional NSAIDs, which inhibit non-selectively both enzymes COX-1 and COX-2, and a new class of selective COX-2 inhibitors.

The skeleton is abundantly supplied with prostaglandins, mainly $\mathrm{PGE}_{2}$, which modulate osteoblastic and osteoclastic function under physiological or pathological conditions. The anabolic effect of $\mathrm{PGE}_{2}$ on bone occurs chiefly in response to mechanical forces and in the healing process ${ }^{24}$. Not surprisingly, considerable experimental and clinical evidence has indicated a risk for reparative bone formation related to the use of selective and non- 
selective NSAIDs in the orthopedic clinic, although an absence of this deleterious effect has also been reported ${ }^{16}$.

Even though the NSAIDs are among the most commonly used drugs for management of acute and chronic pain in clinical dentistry ${ }^{23}$, very few studies have been conducted to assess their effects on alveolar bone. A small number of experimental investigations have suggested the deleterious effect of conventional NSAIDs on alveolar bone healing 2,30 and some clinical assessments have reported no significant difference in the rate of bone healing following administration of this kind of drug 3,4,17. $^{3}$.

Ketorolac is a conventional (non-selective) NSAID which, in low doses, has a preferential COX-1 inhibitory effect ${ }^{29}$ while etoricoxib is a new selective COX-2 inhibitor ${ }^{21,26}$. Literature data have suggested that ketorolac can interfere negatively with new bone formation in different experimental models (femur fracture healing, spinal fusion and ulna osteotomy in rats and rabbits) ${ }^{11,15}$ in opposition to one report stating that ketorolac does not interfere with tibia fracture repair in mouse ${ }^{18}$. To the best of our knowledge, there are no reports about the effects of etoricoxib on bone repair, except for few studies showing its beneficial action in experimental periodontitis.

Since the 1970s, paracetamol/acetaminophen has become one of the most popular and widely used drugs in the world for treatment of pain and fever $^{6}$, and one of the first choices for pain control in clinical dentistry ${ }^{20}$. Although it is generally considered an ineffective or weak anti-inflammatory drug, paracetamol seems capable of inhibiting COX2 activity in inflammatory sites ${ }^{12}$. In spite of this, treatment of rats with paracetamol did not hinder femur fracture healing ${ }^{5}$.

The purpose of the present study was to investigate whether paracetamol, ketorolac or etoricoxib may have a detrimental effect on alveolar bone formation, considering the filling of rat extraction socket with newly formed bone as experimental model.

\section{MATERIAL AND METHODS}

Male Wistar rats (about $250 \mathrm{~g}$ initial body weight) were anaesthetized with a solution of ketamine hydrochloride (Ketamina Agener, União Química Farmacêutica Nacional S/A, Embu-Guaçu, $\mathrm{SP}$, Brazil; $75 \mathrm{mg} / \mathrm{kg}$ ) and xylazine (Dopaser, Laboratórios Calier S/A, Barcelona, Spain; $10 \mathrm{mg} /$ $\mathrm{kg}$ ) administered intraperitoneally, and had the upper right incisors extracted and the wounds sutured with mononylon 4-0 (Ethicon, Johnson \& Johnson, São José dos Campos, SP, Brazil). A single dose $(0.2 \mathrm{~mL}$ per rat, intramuscularly) of a polyvalent veterinary antibiotic (Pentabiótico
Veterinário, Wyeth, São Bernardo do Campo, SP, Brazil) was administered immediately after surgery and 5 days later.

Treated rats received oral doses of $1 \mathrm{~mL}$ aqueous solution of paracetamol (Paracetamol; Biossintética Farmacêutica Ltda, São Paulo, SP, Brazil - 80 mg/ kg/rat/day), ketorolac (Toragesic; Sigma Pharma, Hortolândia, SP, Brasil $-4 \mathrm{mg} / \mathrm{kg} /$ day) or etoricoxib (Arcoxia; Merck do Brasil, São Paulo, SP, Brazil; $10 \mathrm{mg} / \mathrm{kg} / \mathrm{day}$ ) administered by gavage from the day of surgery until death, 2 weeks later. Control rats received tap water ( $1 \mathrm{~mL} /$ day by gavage). The animals were housed under climate-controlled environment ( $12 \mathrm{~h}$ light $/ 12 \mathrm{~h}$ dark, $20-24^{\circ} \mathrm{C}$ ) with free access to standard laboratory chow and tap water. All procedures were conducted in compliance with ethical principles for animal research, as approved by institutional guidelines (Protocol CETEA 117/2006).

The animals were killed with an intraperitoneal overdose of sodium pentobarbital 2 weeks postoperatively and their heads were immersed in $10 \%$ formalin solution for $48 \mathrm{~h}$. After fixation, the maxillae were dissected free, decalcified and processed for paraffin embedding. Semi-serial longitudinal $6-\mu \mathrm{m}$-thick sections of the hemimaxillae containing the alveolar sockets were cut at $60-\mu \mathrm{m}$ intervals and stained with hematoxylin and eosin.

For histometric analysis, the degree of new bone formation inside the alveolar socket was estimated by a differential point-counting method, using an optical microscopy (Zeiss Axiostar Plus; Carl Zeiss, Jena, Germany) with a digital camera for image capture (Zeiss Axiocam IC; Carl Zeiss) and a public domain histometry software (Image J, version 1.38, Mental Health Institute, Bethesda, Maryland, USA). The healing process, which in this phase consists of a gradual replacement of connective tissue by bone trabeculae, was estimated by new bone volume fraction ( $\%$ bone trabeculae relative to bone trabeculae plus connective tissue). A total of 1100-1300 points were counted in 8-9 histological sections per alveolus (final magnification $\times 100$ ), the percentage of points lying on bone trabeculae being proportional to their volume density. The measurements were standardized in the cervical and apical alveolar thirds, in order to avoid interference of regional differences in the rate of bone healing. Differences between groups were analyzed by ANOVA ( $p<0.05$ for statistical significance) after confirming a normal distribution of sample data (Kolmogorov-Smirnov normality test, $p>0.10$ ).

\section{RESULTS}

Histological examination showed the alveolar socket of control rats (Figure $1 \mathrm{~A}$ ) occupied by 

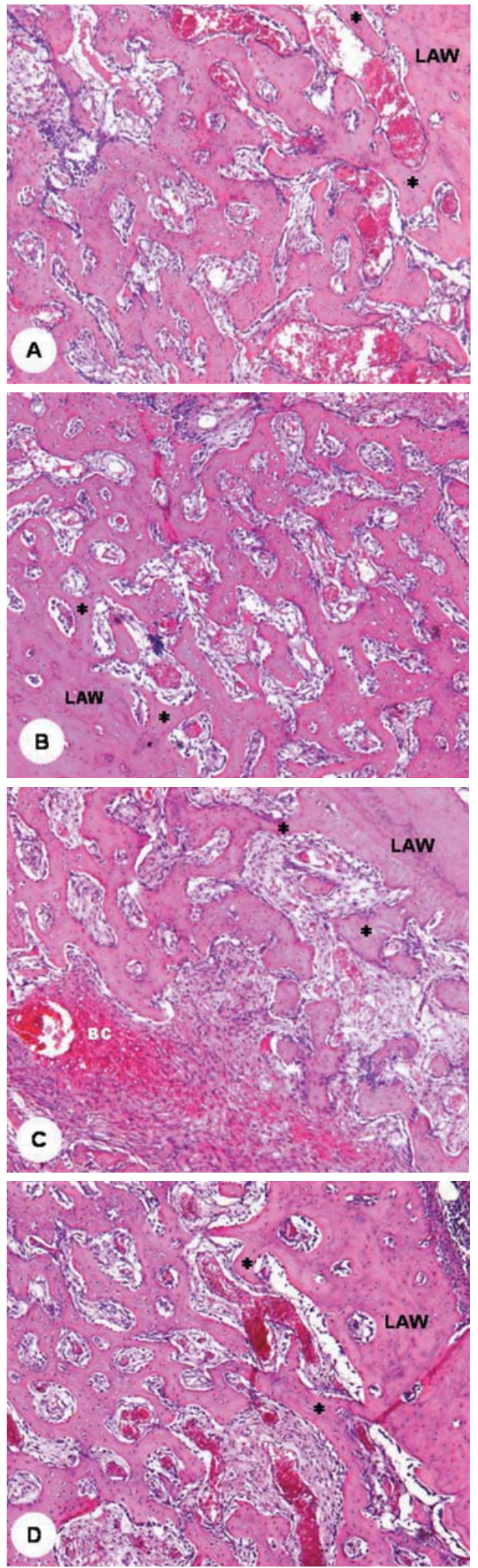

Figure 1- Rat alveolar sockets at 2 weeks after tooth extraction (hematoxylin and eosin; original magnification $\times 50$ ). New bone trabeculae $(*)$ forming from the inner surface of the lateral alveolar wall (LAW) in a control rat $(A)$ and in rats treated with paracetamol $(B)$, ketorolac $(C)$ and etoricoxib (D); blood clot remnant (BC) interposed among new bone trabeculae in a ketorolac-treated rat

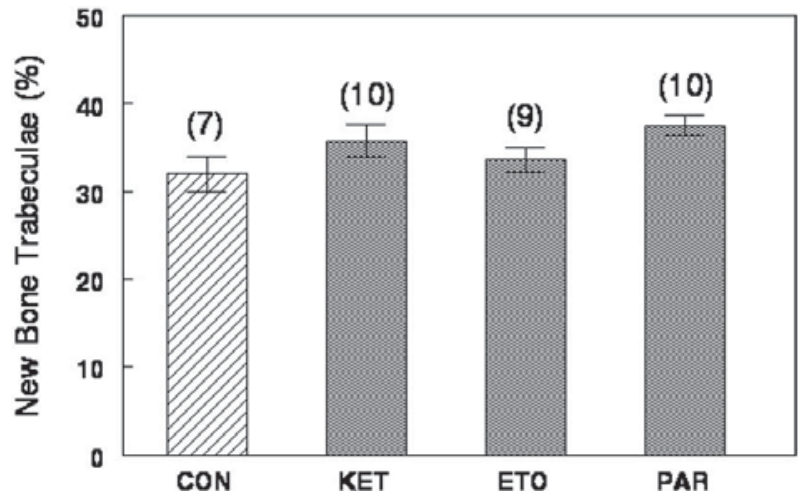

Figure 2- Percent of new bone trabeculae (mean \pm standard error of mean) inside the alveolar socket, 2 weeks after tooth extraction, in control (CON) rats and in rats treated with ketorolac (KET), etoricoxib (ETO) and paracetamol (PAR)

connective tissue and a network of delicate bone trabeculae lined with osteoblasts, forming from the inner surfaces of the alveolar walls. Blood clot remnants were still observed, mainly in the central region of the apical and middle alveolar thirds. In rats treated with paracetamol (Figure 1B), ketorolac (Figure 1C) or etoricoxib (Figure 1D), the bone healing process did not show any noticeable difference as compared to the controls.

Histometric data confirmed histological observation that neither paracetamol nor ketorolac or etoricoxib affected significantly the volume fraction of bone trabeculae forming inside the alveolar socket (Figure 2).

\section{DISCUSSION}

In the present study, the intra-alveolar healing process in the control and treated groups closely resembled literature data. Briefly, after tooth extraction, the socket is filled with blood clot, which is progressively invaded by capillary sprouting and fibroblasts originating from periodontal ligament remnants; in the sequence, the coagulum is gradually absorbed and replaced by immature connective tissue, the amount of inflammatory cells and blood vessels decreases and the osteoblasts become evident. The osteoblasts initially synthesize an immature bone matrix that is further mineralized by calcium deposition as hydroxyapatite crystals. New alveolar bone formation takes place from the apical and lateral walls towards the center, and the healing process culminates with filling of the dental socket by trabecular bone ${ }^{7,8}$. It has been confirmed that, in rats, the major proportion of bone formation ${ }^{13}$ and the maximum mineral bone density ${ }^{8}$ take place by the end of the $2^{\text {nd }}$ week after tooth extraction, which was the period elected for bone healing measurement in the present study.

In the present study, neither NSAIDs, ketorolac 
and etoricoxib, interfered with rat alveolar bone repair two weeks after tooth extraction.

Studies regarding the effect of COX inhibition on alveolar bone healing are scarce and refer only to non-selective NSAIDs ${ }^{10}$. A histological study was conducted to investigate the effects of longterm treatment with aspirin cones placed in the extraction sockets of dogs ${ }^{2}$. The authors reported delayed alveolar bone formation in the 2-week samples, but not after long-term treatment, and admitted limitations in the experimental model that allowed the drug to stay in the sockets only for 2-3 days. In rats, short-term treatment (4 days) with diclofenac also delayed alveolar socket healing ${ }^{30}$. Clinical investigations are equally rare and pertain to short-term administration of NSAIDs to control edema and pain after removal of impacted third molars. Based on clinical postoperative assessment, some surgeons have reported no significant difference in the rate of bone healing following administration of ibuprofen ${ }^{17}$ aspirin, diclofenac ${ }^{4}$ and flurbiprofen ${ }^{3}$.

Contrarily, a wide range of experimental and clinical data have confirmed that a non-selective inhibition of COX-1 and COX-2 by the conventional NSAIDs (indomethacin, ibuprofen, naproxen, ketorolac) can interfere negatively with long bone fracture healing and spinal fusion rate, although an absence of this deleterious effect has also been reported. Many experimental and clinical studies were also conducted to verify the effects of selective COX-2 NSAIDs and, despite the importance of COX2 and $\mathrm{PGE}_{2}$ for bone formation, the results are also controversial. In addition to evidence showing that the coxibs (rofecoxib, celecoxib and parecoxib) inhibit long bone repair in rats and rabbits, there are some reports stating that they do not interfere with fracture repair and spinal fusion rate, both in rodents and humans ${ }^{16}$.

Factors such as dosage and duration of treatment, as well as age, intra- and inter-species differences regarding sensitivity to drugs, compensatory local and systemic factors, pharmacokinetics of drugs in laboratory animals compared to humans and rate of bone remodeling 9,18,24 have been considered responsible for the controversies in the experimental results about the effects of COX inhibitors on bone healing.

In rats, ketorolac used in small doses is considered a preferential COX-1 inhibitor (3 mg/ $\mathrm{kg} /$ day inhibits $95 \%$ of COX-1 without a significant inhibition of COX-2 activity) ${ }^{28}$, and can hinder femur fracture healing ${ }^{11}$. A recent in vitro study investigated the effect of ketorolac (among seven COX-1 and COX-2 inhibitors) on the marrow stem cell (MSC) potential for proliferation and differentiation towards the osteogenic and chondrogenic lineages. Although none of the drugs affected significantly
MSC proliferation and osteogenic differentiation, some of them (mostly ketorolac) inhibited bone formation via blockage of MSC chondrogenic differentiation, which is an important intermediate phase in endochondral bone formation, such as in bone fracture healing 22 .

Etoricoxib is a selective COX-2 inhibitor (can block COX-2 activity 106 times $^{28}$ or 344 times $^{21}$ more than COX-1 activity). In the same dose as that used in the present study, it can control hiperalgesia ${ }^{26}$ and reduce bone loss in periodontal disease ${ }^{1}$, in rats. In 2008, the Brazilian Agency of Sanitary Surveillance (ANVISA) suspended commercialization of $120 \mathrm{mg}$ pills of etoricoxib, but allowed the sale of 60 and $90 \mathrm{mg}$ pills provided the retention of medical prescription and inclusion of adverse effects warning in the bulla were done. Thus, remains the interest of the present study regarding long-term use of this drug for controlling chronic pain associated to musculoskeletal disorders and rheumatoid diseases as well as an experimental selective COX-2 inhibitor.

Paracetamol is a potent analgesic and antipyretic with a central mechanism of action still not completely understood. It has been claimed that this drug, unlike the NSAIDs, devoid a significant inhibition of peripheral prostanoids, presenting thus a weak or ineffective anti-inflammatory effect ${ }^{6}$. However, a recent study carried out with human volunteers showed that paracetamol promotes more than $80 \%$ inhibition of peripheral COX-2, which is comparable to selective NSAIDs ${ }^{14}$.

Studies carried out in the late 1990 s revealed a second peak of COX-2 occurring in the resolution phase of the inflammatory process, and showed that this COX-2 has a reduced sensibility to NSAIDs but is highly sensitive to inhibition with paracetamol $^{27}$. Inhibition of this late-appearing COX-2 with NSAIDs delayed resolution of the inflammatory process, suggesting that this enzyme may present a proinflammatory action during the early phases, but may contribute to resolution of the inflammatory reaction and the healing process at a later phase ${ }^{20}$. It was recently confirmed that prostaglandins produced by activation of COX-2 are important factors that mediate resolution of the inflammatory process ${ }^{25}$.

All things considered, it could be supposed that paracetamol, inhibiting locally the lateappearing COX-2, would delay the resolution of the inflammatory process elicited by tooth extraction and hinder the subsequent bone healing. However, the supposed detrimental effect of paracetamol on alveolar bone healing was not confirmed in the present study.

A dose of paracetamol ( $80 \mathrm{mg} / \mathrm{kg} /$ day) compatible to human therapy and in the range of investigations carried out in laboratory animals was used in the 
present study. Experimental studies dealing with the analgesic effect of paracetamol have employed a single dose (acute treatment) of $850 \mathrm{mg} / \mathrm{kg}^{19}$ and investigations about its effect on the healing of soft and mineralized tissues have used dosages of 60 to $300 \mathrm{mg} / \mathrm{kg} / \mathrm{day}$, for up to 14 days (prolonged treatment $)^{5}$. In the same way as observed in the present study, treatment of rats with paracetamol/ acetaminophen ( 60 or $300 \mathrm{mg} / \mathrm{kg} /$ day for 10 days) had no negative effect on femur fracture healing, as observed 8 weeks later by radiographic and histological examination as well as by mechanical testing. It is worth mentioning, however, that no assessment was made immediately after treatment completion 5 . Acetaminophen administered in standard concentrations in the food at an average dosage of $60 \mathrm{mg} / \mathrm{kg} /$ day during 14 days also had no detrimental effect on the healing of rat patellar tendon ${ }^{8}$.

\section{CONCLUSION}

Histometric data showed that prolonged treatment ( 2 weeks) with ketorolac (exerting a preferential COX-1 inhibition), etoricoxib (a selective COX-2 inhibitor) or paracetamol (a weak NSAID supposedly capable of inhibiting COX-2 activity in inflammatory sites) did not interfere negatively with alveolar bone healing, in rats.

\section{REFERENCES}

1- Azoubel MC, Menezes AM, Bezerra D, Oriá RB, Ribeiro RA, Brito GA. Comparison of etoricoxib and indomethacin for the treatment of experimental periodontitis in rats. Braz J Med Biol Res. 2007;40:117-25.

2- Baratieri A, Deli R. The effect on bone repair of aspirin cones placed in extraction sockets in dogs: a histopathologic study. J Oral Pathol. 1979;8:198-206.

3- Battisti N. The evaluation of the analgesic and anti-inflammatory effects of flurbiprofen mouthwash and $100-\mathrm{mg}$ tablets in oral medicine. Minerva Stomatol. 1994;43:141-4.

4- Bailey BM, Zaki G, Rotman H, Woodwards R. A double-blind comparative study of soluble aspirin and diclofenac dispersible in the control of postextraction pain after removal of impacted third molars. Int J Oral Maxillofac Surg. 1993;22:238-41.

5- Bergenstock M, Min W, Simon AM, Sabatino C, O'Connor JP. A comparison between the effects of acetaminophen and celecoxib on bone fracture healing in rats. J Orthop Trauma. 2005;19:717-23. 6- Bertolini A, Ferrari A, Ottani A, Guerzoni S, Tacchi R, Leone S. Paracetamol: new vistas of an old drug. CNS Drug Rev. 2006;12:250-75.

7- Carvalho TL, Bombonato KF, Brentegani LG. Histometric analysis of rat alveolar wound healing. Braz Dent J. 1997;8:9-12.

8- Elsubeihi ES, Heersche JN. Quantitative assessment of postextraction healing and alveolar ridge remodelling of the mandible in female rats. Arch Oral Biol. 2004;49:401-12.

9- Ferry ST, Dahners LE, Afshari HM, Weinhold PS. The effects of common anti-inflammatory drugs on the healing of rat patellar tendon. Am J Sports Med. 2007;35(8):1326-33.

10- Fracon RN, Teófilo JM, Satin RB, Lamano T. Prostaglandins and bone: potential risks and benefits related to the use of nonsteroidal anti-inflammatory drugs in clinical dentistry. J Oral Sci. 2008;50:247-52.
11- Gerstenfeld LC, Al-Ghawas M, Alkhiary YM, Cullinane DM, Krall $E A$, Fitch $J$, et al. Selective and nonselective cyclooxygenase-2 inhibitors and experimental fracture-healing. Reversibility of effects after short-term treatment. J Bone Joint Surg. 2007;89:114-25. 12- Graham GG, Scott KF. Mechanism of action of paracetamol. Am J Ther. 2005;12:46-55.

13- Guglielmotti MB, Cabrini RL. Alveolar wound healing and ridge remodeling after tooth extraction in the rat: a histologic, radiographic and histometric study. J Oral Maxillofac Surg. 1985;43:359-64.

14- Hinz B, Cheremina O, Brune K. Acetaminophen (paracetamol) is a selective cyclooxygenase-2 inhibitor in man. FASEB $J$. 2008;22:383-90.

15- Ho ML, Chanq JK, Wang GJ. Antiinflammatory drug effects on bone repair and remodeling in rabbits. Clin Orthop Relat Res. 1995;313:270-8.

16- Lamano Carvalho TL. Effect of conventional and COX-2 selective non-steroidal antiinflammatory drugs on bone healing. Acta Ortop Bras. 2007;15:166-8.

17- Lökken P, Olsen I, Bruaset I, Norman-Pedersen K. Bilateral surgical removal of impacted lower third molar teeth as a model for drug evaluation: a test with ibuprofen. Eur J Clin Pharmacol. 1975;8:209-16.

18- Mullis BH, Copland ST, Weinhold PS, Miclau T, Lester GE, Bos GD. Effect of COX-2 inhibitors and non-steroidal anti-inflammatory drugs on a mouse fracture model. Injury 2006;37:827-37.

19- Ottani A, Leone S, Sandrini M, Ferrari A, Bertolini A. The analgesic activity of paracetamol is prevented by blockade of cannabinoid CB1 receptors. Eur J Pharmacol. 2006;531:280-81.

20- Parente L. Pros and cons of selective inhibition of cyclooxygenase-2 versus dual lipoxygenase/cyclooxygenase inhibition: is two better than one? J Rheumatol. 2001;28:2375-32. 21- Patrignani P, Capone ML, Taconelli S. Clinical pharmacology of etoricoxib: a novel selective COX-2 inhibitor. Expert Opin Pharmacoter. 2003;4:265-84.

22- Pountos I, Giannoudis PV, Jones E, English A, Churchman S, Field $\mathrm{S}$, et al. NSAIDS inhibit in vitro MSC chondrogenesis but not osteogenesis. J Cell Mol Med. 2010. Epub ahead of print.

23- Poveda Roda R, Bagán JV, Jiménez Soriano Y, Gallud Romero L. Use of nonsteroidal antiinflammatory drugs in dental practice. A review. Med Oral Patol Oral Cir Bucal. 2007;12(1):E10-8.

24- Radi ZA, Khan NK. Effects of cyclooxygenase inhibition on bone, tendon and ligament healing. Inflamm Res. 2005;54:358-66. 25- Rajakariar R, Yaqoob MM, Gilroy DW. COX-2 in inflammation and resolution. Mol Interv. 2006;6:199-207.

26- Rindeau D, Percival MD, Brideau C, Charleson S, Dube D, Ethier $D$, et al. Etoricoxib (MK-0663): preclinical profile and comparison with other agents that selectively inhibit cyclooxygenase-2. J Pharmacol Exp Ther. 2001;296(2):558-66.

27- Simmons DL, Botting RM, Robertson PM, Madsen ML, Vane JR. Induction of an acetaminophen-sensitive cyclooxygenase with reduced sensitivity to nonsteroid antiinflamatory drugs. Proc Natl Acad Sci USA. 1999;96:3275-80.

28- Wallace JL, McKnight W, Reuter BK, Vergnolle N. NSAIDinduced gastric damage in rats: requirement for inhibition of both cyclooxygenase 1 and 2. Gastroenterology. 2000;119:706-14.

29- Warner TD, Giuliano F, Voinovic I, Bukasa A, Mitchell JA, Vane JR. Nonsteroid drug selectivities for cyclo-oxygenase-1 rather than cyclo-oxygenase-2 are associated with human gastrointestinal toxicity: a full in vitro analysis. Proc Natl Acad Sci USA. 1999;96:7563-8.

30- Yugoshi LI, Sala MA, Brentegani LG, Lamano Carvalho TL. Histometric study of socket healing after tooth extraction in rats treated with diclofenac. Braz Dent J. 2002;13:92-6. 